\title{
Direitos autorais nas obras musicais sob a ótica da lei no 9.610 de $1998^{1}$
}

Francisco Robério Fernandes Júnior ${ }^{2}$

\section{RESUMO}

A arte da música define-se em organizar de forma singular uma combinação coerente de sons e silêncios que se desenvolvem ao longo do tempo. Para isso, são usados os princípios fundamentais da melodia, a harmonia e o ritmo. Música, como elemento cultural e artístico, tem o poder impactar e causar reflexos nas mais variadas esferas, dentre elas, as sociais, as políticas e as jurídicas. Manifestações públicas com seus coros incisivos e músicas que envolvem temas de corrupção são exemplos de meios pelos quais influenciam-se os pensamentos de multidões, onde, não importando a época em que a letra foi escrita, parece sempre bastante atual. Um exemplo que retrata bem essa atualidade pode ser ouvido na música "Capital Inicial - Que País é Esse", que traz na composição uma crítica dura à corrupção, um dos principais problemas do nosso país ao longo da história, raiz de inúmeros outros problemas sociais, a exemplo dos desvios de verbas públicas, sonegações fiscais, precariedades na saúde, lazer e educação por carência de investimentos que deveriam ser efetivados nestas áreas. Por mais que os anos passem, os problemas e as práticas parecem continuar as mesmas.

Palavras-chave: Música. Direitos autorais. Propriedade intelectual. Internet. Intérpretes.

1 Data de Recebimento: 30/07/2019. Data de Aceite: 20/09/2019.

2 Advogado. Graduado em Direito pelo Centro Universitário 7 de Setembro - UNI7. Pós-graduado em Direito Processual Civil pela Escola Superior do Ministério Público - ESMP. Foi monitor das disciplinas de Direito Civil III e Direito Processual Civil II. E-mail: roberiofernandesjr@gmail.com 


\section{INTRODUÇÃO}

Para ser considerado atual, um tema não precisa ser novo, um tema de cem anos pode ser considerado atual pelo fato de estar sempre surgindo novos elementos para agregar e enriquecer o seu debate, como é o caso dos direitos autorais. Direito autoral não é um debate novo, mas é enriquecido pelos inúmeros elementos que aparecem a todo momento com as novas tecnologias e inovações trazidas pela contemporaneidade.

Para tratar desse assunto tão rico, criou-se uma lei que regula, atualiza e consolida a legislação referente aos direitos autorais, que está em vigor no Brasil por via da Lei no 9.610/98. Há inúmeros conflitos de direitos no âmbito dos direitos autorais e, por meio desta legislação, pode-se entender como funcionam, são dirimidos e resolvidos muitos deles, tendo em vista que, de um lado, há o direito ao acesso à cultura e, de outro, tem-se o direito de proteção à produção intelectual feita pelo autor daquela obra no qual, em muitas ocasiões, esses direitos irão entrar em choque um com o outro.

Quando se fala em direitos autorais incluem-se tanto os direitos do autor quanto os que lhe são conexos, a exemplo dos direitos de artistas executantes, produtores ou intérpretes da sua obra, ou seja, não é um direito unicamente do compositor, mas também de todos os artistas que agregam valores à obra.

Uma ramificação bastante polêmica, quanto à temática dos direitos autorais, são os desdobramentos que surgem da relação entre os direitos do autor e o advento da internet, que revolucionou e revoluciona os meios de comunicação a todo o momento, gerando novas informações, e interligando pessoas de uma maneira nunca vista antes, passando a ditar novas regras de comunicação e comportamento, bem como a utilização de novas palavras e gírias oriundas desse impacto.

Tanto há reflexos positivos quanto negativos dessa relação e, a 
partir desses novos meios de comunicação, como a internet, surgem dúvidas em relação ao ambiente no qual ela se encontra, a exemplo de como o direito se molda e se adapta a essas novas questões por ela trazidas, e quais são os limites que seus usuários devem ter quanto à divulgação e utilização de obras musicais.

\section{DIREITOS MORAIS E DIREITOS PATRIMONIAIS DO AUTOR}

Os direitos de autor são conferidos à pessoa física que criou a obra literária, artística ou científica, conforme o disposto no artigo 11, da Lei 9.610/98, "autor é a pessoa física criadora da obra literária, artística ou científica" (BRASIL, 1998, online). Acontece que a proteção concedida ao autor não é exclusiva da pessoa física, pois, no parágrafo único do referido artigo, é concedida tal proteção também às pessoas jurídicas, nos casos previstos na lei supracitada.

No âmbito das obras musicais, tem-se como autor o compositor, sendo esse o indivíduo originário do direito de autor, nos casos de obra com apenas um autor, havendo mais de um, é instituída a coautoria, a qual legitima todos aqueles autores da respectiva obra ao seu exercício, tanto dos direitos morais quanto dos direitos patrimoniais da condição de autor. Ratificando o exposto, explana Dias:

\footnotetext{
Quando se fala em direitos autorais, na realidade a expressão engloba Direitos de Autor, que no caso de obras musicais são os compositores. Bem como os Direitos Conexos, de que são titulares os artistas intérpretes ou executantes, as produtoras fonográficas e as empresas de radiodifusão, nos termos dos dispositivos do diploma autoral. (2000, p. 21).
}

Quando se fala em direitos conexos, são tidos como conexos aqueles que fariam uma espécie de ramificação dos direitos de autor, ou seja, quando, no caso específico de uma música que é composta e interpretada por pessoas diferentes, o executante da obra seria 
em tese titular de um direito conexo em relação ao direito de autor.

É importante ressaltar que não é obrigatório ao autor se identificar com o seu nome verdadeiro. Na qualidade de compositor da obra, ele pode identificar-se pelo seu nome civil, completo, bem como abreviado, chegando à possibilidade até mesmo de indicar somente as iniciais do seu nome, pseudônimo ou qualquer outro meio que seja convencional e faça-lhe alusão. Tal ideia é trazida de forma bem clara por Pedro Paranaguá e Sérgio Branco:

\begin{abstract}
Assim como é comum que atores e atrizes usem nomes artísticos, também autores podem se apresentar com pseudônimos. O famoso escritor Marcos Rey, autor de Malditos paulistas, Memórias de um gigolô e diversos livros infanto-juvenis, tinha por nome verdadeiro Edmundo Donato. Por sua vez, o internacionalmente conhecido Mark Twain se chamava Samuel Longhorne Clemens. O poeta Edward Estlin Cummings se identificava apenas como E. E. Cummings, e o músico Prince Rogers Nelson decidiu, durante

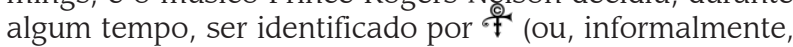
o Artista Anteriormente Conhecido como Prince). (2009, p. 40, grifo do autor).
\end{abstract}

A proteção dos direitos do autor inicia-se no momento da criação da obra, e a acompanha até o prazo de 70 (setenta) anos após a morte do autor. O direito autoral não é perpétuo e, a partir dessa afirmação, abre-se destaque para a questão do domínio público. A proteção tem um prazo que, quando esgotado, deixa de pertencer àquele domínio que era privado, e passa a ser de domínio público. Esse prazo, no Brasil, é vigente por 70 (setenta) anos, contados a partir do dia primeiro de janeiro do ano subsequente ao falecimento do autor (BRASIL, 1998, online).

Quando as obras se encontram na situação de pertencer ao domínio público, não há mais que se falar de proteção com relação ao âmbito privado, sendo assim, deixam de estar sob a égide da Lei $n^{\circ}$ 9.610/98. Isto acontece em benefício cultural da população, pois é dado um tempo extremamente razoável para que os autores extraiam 
os recursos condizentes com a utilização de sua obra, mas se permite sopesar essa situação para que a balança da equidade fique estável para ambos os lados.

Por isso, é recomendado a quem deseje utilizar determinada obra, dirigir-se aos sites oficiais correspondentes a ela, para saber se esta se encontra ou não em domínio público, pois, dessa maneira, evita-se o uso, mesmo que de forma não intencional, irregular da obra e consequentemente a violação dos direitos autorais desta.

Mesmo em domínio público deve-se respeitar os créditos da criação da obra do autor, inclusive fazendo jus à obrigação de citação da autoria e fonte da obra. Dessa forma, a lição de Fabio Maria de Mattia: "O direito de autor é composto por duas realidades jurídicas independentes, por dois direitos distintos, sendo que cada um obedece às regras especiais que dirigem sua própria natureza: o direito moral e o direito pecuniário". (1975, p. 38).

A atual Constituição Federal, de 1988, garante aos autores, no título dos direitos e garantias individuais, o direito exclusivo à utilização, publicação e reprodução de suas sobras (BRASIL, 1988, online). Não obstante a possibilidade de fiscalização do aproveitamento econômico, que possa vir a surgir com as suas criações, nem a extensão desses direitos aos intérpretes, tendo em vista que são englobados pelos direitos de autor. Preocupa-se o legislador de conferir esse aspecto patrimonial para os direitos autorais.

De todas as criações intelectuais, a musical é a que abre um maior espaço ao maior número de especificações do direito autoral, nos campos dos direitos de reprodução, de exploração ou patrimonial. São inúmeras questões que podem surgir ao se incluir o elemento econômico na discussão. Enuncia bem o professor Ascensão quando conclui:

Se a finalidade da lei não é atribuir o exclusivo, mas o exclusivo como via de atribuição de vantagens patrimoniais, devem ser consideradas livres aquelas atividades que não tiverem nenhuma incidência negativa na exploração eco- 
nômica da obra. Um ato que não possa prejudicar em nada a exploração econômica da obra é, por força da teleologia legal, um ato livre. (ASCENSÃO, 1997, p. 161).

Em casos de coautoria, ou seja, quando há mais de um autor ou compositor em uma mesma obra, nenhum dos autores pode, se esta for indivisível, publicá-la ou autorizar que ela seja publicada sem que os demais tenham consentido com tal prática. A atividade de coautoria tem seus bônus, mas também seus ônus, e esse é um deles, uma vez que estas possibilidades devem ser consideradas e ponderadas na atividade de criação.

No Brasil, o pensamento é de que os direitos morais do autor estão intimamente ligados à atividade criadora, até por adotar o sistema francês, que versa sobre esse tema de modo mais abrangente do que o sistema inglês, que sequer engloba tais direitos morais no campo dos direitos autorais. Dessa forma, são tidos como direitos personalíssimos daqueles que criaram as obras e, por consequência, intransmissíveis e irrenunciáveis.

Por esse pensamento, não se transmite o direito nem mesmo quando há a alienação dos direitos patrimoniais daquela obra, sendo amparado pela lei no tocante a esse ponto. Conforme o art. 24 da Lei $n^{\circ}$ 9.610/98, têm-se como exemplo de direitos morais do autor: reivindicar, a qualquer tempo, a autoria da obra, ter seu nome, pseudônimo ou sinal convencional indicado ou anunciado, como sendo o do autor, na utilização de sua obra, e conservar a obra inédita (BRASIL, 1998, online).

Ainda no campo dos exemplos, tem-se o direito de assegurar a integridade da obra, opondo-se a quaisquer modificações ou à prática de atos que, de qualquer forma, possam prejudicá-la ou atingi-lo, como autor, em sua reputação ou honra. O direito de modificar a obra, antes ou depois de utilizada, e o de retirar de circulação a obra, ou de suspender qualquer forma de utilização já autorizada, quando a circulação ou utilização implicar em afronta à sua reputação e 
imagem (BRASIL, 1998, online).

Um interessante ponto que é explorado dentro do âmbito musical é elaboração de paródias musicais. Paródia, lato sensu, é toda e qualquer releitura de uma obra, seja ela musical, literária ou cinematográfica, onde são utilizados elementos cômicos e irônicos, mantendo a estrutura da obra original para formar uma nova obra, porém, preservados alguns elementos gerais da obra paradigma.

Portanto, a paródia musical é uma recriação de uma obra já concebida, com adaptações, representando importante elemento no modernismo brasileiro a qual, há décadas, é amplamente utilizada no âmbito televisivo e atualmente, ganha cada vez mais espaço na internet.

Dessa forma, o conhecimento dos direitos morais dos titulares desses direitos autorais é de suma importância para entender os aspectos seguintes que são abordados em relação à sistemática com o que já fora exposto, bem como os direitos patrimoniais de exclusividade, fiscalização do aproveitamento econômico gerado pelas obras, autorização prévia e expressa com relação à utilização da obra por quaisquer modalidades reguladas, tais como edição, reprodução parcial ou integral, adaptação, distribuição e inclusão de dados.

Diante do exposto, conclui-se que os direitos do autor devem ser respeitados, mas tendo-se em mente que esses direitos não são irrestritos e ilimitados, pois se assim fossem, não se tratariam de direito e sim de arbítrio. Dessa forma, são diversos os casos em que não há ofensa ao direito de autor, como em reproduções na imprensa, reprodução de um exemplar de pequenos trechos, e citações de letras de músicas na comunicação impressa ou auditiva como alguns a serem citados.

Inclusive, não ofendem os direitos de autor as paráfrases e paródias que não forem legítimas reproduções da obra originária, nem lhe implicarem descrédito (BRASIL, 1998, online). Acontece que o legislador, aqui, é um tanto quanto omisso e deixa a interpretação 
bastante subjetiva do que seria ou não um descrédito, devendo ser analisado no caso concreto.

O caminho a ser trilhado pelos direitos de autor deve ser alinhado às evoluções e avanços da tecnologia, tentando manter uma paridade nesta linha de evolução, ou seja, tentar melhorar a medida do aperfeiçoamento daquela para que não fique engessado e parado no tempo, assim como os demais direitos.

\title{
3 TITULARES E OBJETO DOS DIREITOS AUTORAIS
}

Sabendo quem são os autores no âmbito musical, tem-se que diferenciá-los dos titulares dos direitos autorais, pois, conceitualmente, não são sujeitos, confundem-se. Ser autor é diferente de ter os direitos inerentes à qualidade de autor. Partindo desse pressuposto, autor somente pode ser pessoa física, ora, se não fosse por uma pessoa natural, um ser humano, não teria como se criar uma composição. As pessoas jurídicas não compõem sozinhas, a não ser que seja por intermédio de uma pessoa física, que tem toda a atividade intelectual de produzi-la. É o que ressalta Abrão:

\begin{abstract}
O sujeito de direito autoral criador de uma obra estética é sempre uma pessoa física, não importando sua condição pessoal, social, política ou jurídica, ou sua crença espiritual. O titular do direito deverá ser uma pessoa física ou jurídica, que adquiriu essa condição por transferência contratual ou decorrência natural (morte do autor). Autor como pessoa jurídica originária, é qualidade adquirida por presunção legal, caso da obra coletiva. (2002, p. 17).
\end{abstract}

Dessa forma, mesmo que a pessoa física seja autora, ela tem a possibilidade, que lhe é conferida por lei, de transferir a titularidade desse seu direito de autor a terceiros, seja uma pessoa física ou uma pessoa jurídica. O autor continuará sendo aquele que criou a obra, mas a titularidade desse direito pode ser dispersa de acordo com a sua vontade e necessidade. 
Em relação às obras musicais, o sujeito originário do direito de autor é o compositor ou letrista, se esta obra for singular, se for plural, ou seja, caso ela tenha dois ou mais compositores ou letristas, entra-se no sistema de coautoria.

Com a instauração da coautoria, os mentores da obra, em sua totalidade e em comum acordo, são legitimados dos direitos morais e patrimoniais referentes àquela obra que foi feita por eles.

As empresas de radiodifusão, artistas intérpretes ou executantes, e o produtor musical também, são sujeitos de direitos autorais, por meio dos direitos conexos.

O compositor, autor da obra musical, tem sob seu intelecto habilidades, experiências e estudos particulares, uma visão singular a qual é expressa por meio de sua música. Quando criada, há a incidência dos direitos autorais para garantir a proteção da obra, não obstante as consequências morais e/ou patrimoniais da inobservância a tal direito.

Com o surgimento da tecnologia de radiodifusão, alargou-se o alcance de contato com a música e suas obras, por intermédio dos primeiros estúdios de emissoras de rádio. A influência causada pelo advento da radiodifusão foi significativa, como traz Antônio Chaves:

A radiodifusão desenvolve junto a cada indivíduo, no mundo inteiro, uma missão de distração, de instrução e de educação cuja importância pode ser exagerada. Não somente aumenta extraordinariamente a divulgação das obras intelectuais, anteriormente feita apenas através de livros, publicações e conferências, como o faz numa instantaneidade análoga à de um jato de luz (...) é indiscutível que a propagação, elemento e condição da produção intelectual, tornou-se facílima e prática, dando ao pensamento uma importância e um poderia qual nunca registrou em qualquer época da história. (1952 p. 100-101).

Com essa enorme abrangência que adquiriu logo após a sua inserção no mercado, a radiodifusão foi procurada inteligentemente pelos 
grandes empreendedores da indústria fonográfica, que possibilitavam ao compositor uma grande oportunidade de reconhecimento, que não havia sido experimentado até então, sem mencionar nos benefícios financeiros que esse acesso ilimitado poderia trazer, tanto de forma reflexiva quanto de forma incisiva.

Assumia, por parte dessa indústria fonográfica, por meio de contrato, a posição de autor-compositor para o criador, ou para terceiros pleitearem os valores devidos relativos à execução de suas obras nas rádios.

No tocante aos intérpretes das obras, que as reproduzem com seus talentos por meio de interpretações, gravações, dando sua forma e ótica à obra, esses também são protegidos, como traz Abrão:

A explicação histórica para o ajuntamento dessas três diferentes categorias de difusores das obras "autorais" num mesmo lado, estaria nessa própria condição de difusores da mesma matéria prima, no desemprego crescente dos artistas em virtude do avanço da tecnologia de gravação de sons e imagens e na pouco expressiva consciência de classe. A fraqueza econômica dos artistas encontrou nos prósperos produtores de fonogramas o apoio necessário à tese da remuneração de suas atuações gravadas, como compensação pela diminuição das apresentações ao vivo, tendo os empresários, de seu turno, utilizado dessa conveniente parceria para também obter o reconhecimento para si de uma remuneração equivalente. Essa remuneração constitui os chamados direitos patrimoniais conexos. (2002, p.47).

São, portanto, conferidos os direitos próprios de autor para eles ou para os intérpretes, de forma análoga, firmando assim o direito conexo e, portanto, as empresas de radiodifusão dependem estritamente da autorização daqueles que delimitam a quantidade de emissões, podendo inclusive ser disponibilizados em arquivos públicos.

Esses sujeitos desfrutam, portanto, dos direitos patrimoniais de impedir a fixação, a radiodifusão e a comunicação ao público de suas interpretações e execuções ao vivo. Tanto lhes são conferidos os direitos patrimoniais como os direitos morais, que constituem impedir omissões escusas ou imotivadas dos seus nomes na obra, bem como criar obstáculos, opor-se ou acrescentar dificuldades no que se refere às interpretações de modo que venham a prejudicar 
a sua imagem e reputação.

Conferir um direito conexo de autor ao produtor pode ser alvo de críticas, pois é posto em debate a sua efetiva participação na composição da obra, seja ela qual for, em que a relação com o produtor trataria de uma proteção ao investimento do qual se extrai a renda e não ao autor em si. Há produtores que visam quanto lucro ele poderá auferir com a obra, mas, por outro lado, tem-se que reconhecer o efetivo trabalho e dedicação intelectual por parte de outros bons produtores, que investem tempo e dinheiro no processo criativo musical, elaborando arranjos, harmonias, gravando e produzindo, dessa forma, parte da música, sendo assim, responsáveis também pela divulgação e pela qualidade final da obra.

O conceito tradicional de produtor musical confunde-se com o do produtor fonográfico, trazido pela Convenção Internacional sobre a Proteção dos Artistas, Intérpretes e Executantes, Produtoras de Fonogramas e Organismos de Radiodifusão (Convenção de Roma sobre Direitos Conexos), que assenta que o "produtor de fonogramas é a pessoa natural ou jurídica que fixa pela primeira vez os sons de uma execução ou outros sons." (FONTES, 2013, online).

Tem-se aqui a possibilidade de uma pessoa jurídica, como uma gravadora, ser sujeito de direitos conexos, mas é importante lembrar que essa possibilidade é oriunda da instrumentalização efetuada pelo seu agente, como o próprio produtor, tendo com isso responsabilidades econômicas sobre a obra, ressaltando Martins Fontes (2013, online):

Nos Estados Unidos, também se evidencia a tendência dos artistas se dedicarem, ao mesmo tempo, à produção musical e às suas carreiras como músicos. Dentre os casos mais conhecidos, citamos Prince, que produziu Madonna, Chaka Kahn e Mavis Staples, assim como Lauryn Hill, cantora de rap responsável pela produção de Aretha Franklin e Whiyney Houston. Já no Brasil, Carlos Eduardo Miranda - renomado produtor musical, responsável por sucessos como Raimundos, skank e O Rappa - diz que "Produtor musical é como o diretor de um filme. O compositor é o roteirista, a banda é o elenco e o arranjador é o cenógrafo". Neste ínterim, faz-se importante ressaltar que o diretor de cinema é detentor de direitos autorais, inclusive o único que exerce os direitos morais em relação ao conjunto da obra $[\ldots]$.

Diante do exposto, percebe-se a importância que os produtores 
podem ter em uma obra musical, e como a sua proteção realmente deve ser efetivada, tendo em vista a dedicação que se tem com uma obra musical, entrando, dessa forma, no sistema de coautoria com o autor da determinada música.

\section{ANÁLISES DE DECISÕES JUDICIAIS NO ÂMBITO DOS DIREITOS AUTORAIS}

Para buscar conhecer melhor o entendimento do sistema judiciário sobre como lidar com os conflitos que surgem acerca dos direitos autorais na música, deve-se procurar saber o que os Tribunais entendem ao julgar as lides acerca dos direitos autorais, tendo como importância prática o precedente firmado, envolvendo casos que se encaixem naquelas mesmas condições e situações.

O recurso AI 738720 PR, que teve como relator o ministro Luiz Fux do Supremo Tribunal Federal (STF), figurando como recorrente principal a Net Paraná Comunicações LTDA. e como recorrido principal o Escritório Centra de Arrecadação e Distribuição (ECAD), diz respeito à discussão sobre utilização de obras musicais em filmes, e outros diversos trabalhos audiovisuais transmitidos na televisão em canais privados, e a necessidade de pagamento de direitos autorais por esse uso.

É sabido que aqueles que utilizam em seus trabalhos obras musicais têm deveres com relação aos direitos autorais daquelas músicas selecionadas, tendo em vista que deve haver autorização do titular, ou do autor, para o emprego e execução da sua obra, pois o titular do direito de autor pode não querer vincular a sua criação à ideologia transmitida no local em que as pessoas terão acesso à sua música.

Quando há venda de ingressos, como é visto em cinemas, quando há cobrança de couvert artístico, observado em bares, ou qualquer outra forma de arrecadação de valores por parte das pessoas que participem daquele ambiente em que há incidência da execução 
musical, a fixação ocorre em cima de um percentual sobre a receita bruta, levando em conta sempre a relevância da música para aquele negócio.

Como se trata de uma atividade de caráter privado, cabe aos próprios titulares dos direitos autorais fixar os valores que entendem por direito, sendo também possível essa fixação ser efetivada pelo ECAD.

Nesse sentido, a Net Paraná Comunicações LTDA., caso utilize obras musicais na sua grade de programações, deve pagar remuneração por essa utilização, e por se beneficiar do impacto positivo que estas músicas trazem aos seus programas, utilizações essas que são reiteradas a cada programação que é exibida. Pelo exposto, o agravo regimental interposto pela empresa recorrente, em desfavor do ECAD foi conhecido, mas teve o seu provimento negado.

Outro precedente importante foi firmado no julgamento do Recurso Especial no 1.597.678 - RJ 2014/0321935-1, julgado pela $3^{\text {a }}$ turma do Superior Tribunal de Justiça, figurando como recorrente a Universal Music Publishing MGB Brasil LTDA. e como recorridos, as empresas Hortigil Hortifruti S/A e MP Publicidade LTDA. - EPP.

Esse recurso especial teve por objeto a impugnação da apelação cível que julgou improcedente o pedido inicial, por entender que não houve reprodução da obra original indevidamente, mas tão somente uma referência à mesma com elementos que alteraram o sentido original, utilizando-se de elementos de comicidade. Essa obra é a música "Garota de Ipanema", a qual houve a alteração da palavra "coisa" por "couve", inferindo a conotação cômica à obra musical.

O precedente firmado pelos ministros foi de que, corroborando a decisão em sede de apelação, a campanha publicitária promovida pelas recorridas não reproduziu de forma idêntica a melodia de coautoria de Tom Jobim e Vinícius de Moraes, havendo uma ínfima referência a um trecho da conhecida canção, porém, alterando a sua poesia original para uma versão satírica, que é a essência de uma paródia musical, cumprindo assim os seus requisitos de caracterização. 
No âmbito das paródias há um ampla liberdade de criação, desde que não implique em uma verdadeira reprodução da obra originária ou que lhe cause descrédito. Superados esses argumentos, não há necessidade de autorização do titular pela a utilização da obra parodiada.

Um importante ponto, que se extrai desse julgado, é a ideia de que o judiciário não pode se travestir de um órgão eminentemente censurador ou avaliador do humor, tendo em vista não se destinar à crítica artística. Contudo, deve ser feito uma análise minuciosa no caso concreto, pois as circunstâncias fáticas que irão determinar se ouve verdadeira reprodução ou depreciação da obra originária, o que envolve o subjetivismo para se aferir o preenchimento dos requisitos que caracterizam ou não a paródia como tal.

Por fim, tem-se o Recurso Especial no 1.238 .730 - SC (201 1/00387646) julgado pelo Superior Tribunal de Justiça. Esse recurso almejava reformar o acórdão proferido pelo Egrégio Tribunal de Justiça do Estado de Santa Catarina. Entende-se, pelo caso, que o ECAD ajuizou uma ação de cobrança em desfavor do município de Canoinhas/SC, onde um evento do município teria deixado de recolher, concomitantemente ao ingresso, os direitos autorais devidos.

É importante destacar que tanto os direitos de autor quanto os seus direitos conexos são amparados pela lei brasileira, ocorre que, apesar de ambos serem tutelados pela lei dos direitos autorais, não se tratam de direitos idênticos. Ressalta o ministro Marco Buzzi que, na compreensão de que no plano internacional, os direitos autorais são distintos dos chamados direitos conexos, considerando-se o Tratado de Berna, de 1886, para defesa dos direitos autorais e o Tratado de Roma, de 1961, em relação à proteção dos direitos conexos, os diversos países que lhe são signatários, inclusive o Brasil, cuidaram de delinear, cada um, a seu modo, sua aplicação.

Infere-se, portanto, que o cachê é pago ao intérprete pelo seu trabalho em cima do palco, que se difere dos valores pagos aos autores 
das obras na forma de retribuição autoral, no qual essas verbas são registradas com natureza distinta pelo fato de poderem ser separadas física e conceitualmente.

Dessa forma, conclui-se, que o cachê recebido pela apresentação não se trata de um direito de autor, mas sim de um direito conexo ao de autor, que é devido aos intérpretes da obra pelo seu trabalho de pôr e agregar sentimentos e conhecimentos pessoais à musica criada por outrem, tendo em vista que ela decorre da relação contratual com o contratante do evento, em que o cantor realiza a sua apresentação em face da contraprestação fornecida pelo contratante que, em regra, é em pecúnia.

Nesse sentido, o pagamento de valores relativos aos direitos de autor em eventos são devidos e diferenciam dos direitos conexos, o qual o ECAD pode cobrar tais direitos de autor não obstante o cachê já pago aos intérpretes da obra.

Como se trata de cobranças separadas, o ECAD pode cobrar os direitos de autor, ainda que os direitos que lhe são conexos tenham sido pagos em forma de cachê, ante o exposto, o recurso foi conhecido e parcialmente provido para que houvesse o pagamento dos valores devidos no tocante aos direitos autorais.

\section{CONCLUSÃO}

O aparecimento de tecnologias, ao longo de toda a história, modificou e modifica o modo de se lidar com esses direitos, em que cada novo instrumento que é criado pode modificar e demandar uma necessidade de mitigação da incidência legal nesses novos instrumentos tecnológicos.

Desde a radiodifusão até a internet, surgiram e surgem desafios a serem tratados pelo Poder Judiciário acerca dessa temática, a exemplo da "pirataria", que fez com que toda a logística das gravadoras e as comunidades jurídicas passassem por uma reestruturação, 
para que conseguissem assimilar um problema dessa magnitude e pudessem criar soluções para resolvê-lo ou tentar reduzir seus impactos negativos.

Não há como exercer uma fiscalização sobre cada um dos computadores dentre os milhões de usuários conectados pelas mais diversas localidades do mundo, o que afrontaria inclusive o direito à privacidade e intimidade de cada um deles, o que não é compatível com um Estado Democrático de Direito.

Há necessidade de um trabalho constante de adaptação dos dispositivos existentes atualmente a cada nova tecnologia que surge e impacta no que já se tem atualmente.

Ante o exposto, urge a necessidade de uma reciclagem constante dos titulares dos direitos autorais para que consigam explorar os frutos que as obras musicais oferecem consoante os meios de tecnologias que surgem, e do Direito para que se consiga promover uma maior harmonia nessa relação a fim de buscar uma coexistência mais harmoniosa.

\section{COPYRIGHT IN MUSICAL WORKS UNDER THE AGE OF LAW No. 9.610 OF 1998}

\section{ABSTRACT}

The art of music is defined in singularly organizing a coherent combination of sounds and silences that develop over time. For this, the fundamental principles of melody, harmony and rhythm are used. Music, as a cultural and artistic element, has the power to impact and cause reflexes in the most varied spheres, among them social, political and legal. Public manifestations with their incisive choirs and songs that involve themes of corruption are examples of ways in which the thoughts of crowds are influenced, where, no matter the time the lyrics were written, it always seems quite current. An example that portrays 
this reality well can be heard in the song "Capital Inicial - Que País es Esse", which brings in a hard criticism of corruption, one of the main problems of our country throughout history, the root of countless other social problems, such as the diversion of public funds, tax evasion, poor health, leisure and education due to lack of investments that should be carried out in these areas. As much as the years go by, problems and practices seem to remain the same.

Keywords: Music. Copyright. Intellectual property. Internet. Interpreters.

\section{REFERÊNCIAS}

ABRÃO, Eliane Y. Direitos de autor e direitos conexos. São Paulo: Ed. do Brasil, 2002.

BITTAR, Carlos Alberto. A Lei de direitos autorais na jurisprudência. São Paulo: Revista dos Tribunais, 1988.

BRANCO JUNIOR, Sérgio Vieira. Direitos Autorais na Internet e o uso de obras alheias. Rio de Janeiro: Lúmen Júris, 2007.

BRASIL. Supremo Tribunal Federal. Agravo Regimental do Agravo de Instrumento n AI 738720 PR. Relator: Ministro Luiz Fux. Brasília, DF, 4 de dezembro de 2012.

Jusbrasil, dez. 2012. Disponível em: http://stf.jusbrasil.com.br/jurisprudencia/23034571/agreg-no-agravo-de-instrumento-ai-738720-pr-stf.

BRASIL. Superior Tribunal de Justiça. Recurso Especial no 1.238 .730 - SC. Recorrente: Escritório Central de Arrecadação e Distribuição (ECAD). Recorrido: Município de Canoinhas. Relator: Ministro Marco Buzzi. Brasília, DF, 19 de novembro de 2013. Jusbrasil, nov. 2013. Disponível em: http://stj.jusbrasil. com.br/jurisprudencia/2481 1859/recurso-especial-resp-1238730-sc-2011-0038764-6-stj/inteiro-teor-24811860.

BRASIL. Superior Tribunal de Justiça. Recurso Especial n 1597678 RJ 2014/0321935-1. Recorrente Universal Music Publishing Mgb Brasil Ltda. Recorridos Hortigil Hortifruti S/A e MP Publicidade Ltda - Epp. Relator Minis- 
tro Ricardo Villas Bôas Cueva. Brasília, DF, 21 de agosto de 2018. Jusbrasil, ago. 2018. Disponível em: https://stj.jusbrasil.com.br/noticias/624143372/ parodia-com-fins-comerciais-ou-lucrativos-nao-viola-lei-de-direitos-autorais?ref=feed.

CHAVEZ, Antonio. Nova lei brasileira de direito de autor. São Paulo: Revista dos Tribunais, 1975.

COZER DIAS, Maurício. Direito autoral. Campinas: LZN Editora, 2002.

COZER DIAS, Maurício. Utilização musical e direito autoral. Campinas: Bookseller, 2000.

DUVAL, Hermano. Violações dos Direitos Autorais. Rio de janeiro: Borsoi, 1985.

FALCÃO, Joaquim et al. Estudo sobre o software livre comissionado pelo Instituto Nacional de Tecnologia da Informação (ITI). Rio de Janeiro: Lumen Juris, 2006.

GONÇALVES, Carlos Roberto. Responsabilidade Civil. 10. ed. São Paulo: Saraiva, 2007.

LEMOS, Ronaldo. Direito, tecnologia e cultura. São Paulo: FGV, 2005. PARANAGUÁ, Pedro; BRANCO, Sérgio. Direitos autorais. Rio de Janeiro: FGV, 2009. (Série FGV Jurídica). Disponível em: http://bibliotecadigital.fgv. br/dspace/bitstream/handle/10438/2756/Direitos\%20Autorais.pdf.

TRIDENTE, Alessandra. Direito autoral: paradoxos e contribuições para a revisão da tecnologia jurídica no século XXI. Rio de Janeiro: Elsevier, 2009. 